\title{
FAKTOR YANG MEMPENGARUHI PEMBERIAN MPASI DINI DI WILAYAH KERJA PUSKESMAS SIANTAN TENGAH
}

\author{
Nisma $^{1}$, Diena Juliana ${ }^{2}$, Asih Lestari ${ }^{3}$ \\ 1.2.3 STIKes Yarsi Pontianak \\ Nisma: Program studi Pendidikan Ners, STIKes Yarsi Pontianak, Jln Panglima A’im, Nomor.1 \\ Pontianak Timur, Kota Pontianak, Kalimantan Barat-78232, E-mail : nismazahra09@gmail.com
}

\begin{abstract}
ABSTRAK
Latar Belakang: ASI merupakan makan awal untuk bayi baru lahir dan ASI eksklusif diberikan kepada bayi selama 6 bulan tanpada adanya tambahan makanan atau cairan lain yang masuk. Sedangkan MPASI (makanan pendamng air susu ibu) diberikan kepada bayi umur 6 bulan keatas ataupun 180 hari. Tujuan Penelitian Untuk mengetahui ada pengaruh antara tingkat pengetahuan dengan pemberian MPASI serta pengaruh sosial budaya dengan dengan pemberian MPASI yang terjadi diwilayah kerja puskesmas siantan tengah. Metode: Penelitian kuantitatif menggunakan studi deskriptif korelasi dengan .pendekatan cross sectional, serta memakai kuesioner ataupun angket sebagai instrumen. Teknik Sampling yang digunakan merupakan total sampling dengan jumlah sampel 30 responden. Analisa data menggunakan chi square, dengan nilai p value $<0,05$. Hasil penelitian: Ada pengaruh anatara tingkat pendidikan dengan pemberiqan MPASI dini dengan hasil nilai analisis yang diperoleh ( $p$ value 0,179 karena nilai signifikansi pada $0,179<0,05$ ). Ada pengaruh antara pekerjaan responden dengan pemberian MPASI dini diperoleh nilai ( $p$ value 0,179 karena nilai signifikansi pada $0,179<0,05$ ). terdapat pengaruh antara tingkat pengetahuan dengan pemberian MPASI dengan hasil nilai $(p$ value $=0,000)$ dan ada pengaruh atara sosial budaya dengan pemberian MPASI denan hasil nilai ( $\mathrm{p}$ value $=0,001)$. Kesimpulan: ada pengaruh yang signifikan anatar tingkat pengetahuan dengan pemberian MPASI dan sosial budaya dengan pemberian MPASI.
\end{abstract}

Kata kunci: MPASI, pengetahuan, sosial budaya.

\begin{abstract}
Background: Breast milk is the first food for newborns and exclusive breastfeeding is given to babies for 6 months without additional food or other fluids entering. Meanwhile, complementary foods (complementary foods for breast milk) are given to babies aged 6 months and over or 180 days. Research objectives to determine whether there is an influence between the level of knowledge with the provision of complementary foods and the sociocultural influence with the provision of complementary foods that occur in the working area of the Central Siantan Health Center. Type of research: quantitative research using a descriptive correlation study with a cross sectional approach, and using a questionnaire as an instrument. The sampling technique used was total sampling with a sample size of 30 respondents. Data analysis used chi square, with p value <0.05. Research result: There was an influence between the level of education and the provision of early complementary foods and the results of the analysis value obtained ( $p$ value 0.179 because the significance value was $0.179<0.05$ ). There is an influence between the respondent's job and the provision of early complementary foods obtained value ( $p$ value 0.179 because the significance value is at $0.179<0.05$ ). There is an influence between the level of knowledge with the provision of complementary foods and the resulting value $(p$ value $=0,000)$ and there is an influence between the socio-culture with the provision of complementary foods and the resulting value ( $p$ value $=0.001$ ). Conclusion: There is a significant level of knowledge with the provision of complementary foods and socio-culture with the provision of complementary foods.
\end{abstract}

keywords: MPASI, knowledge, socio-culture 
PENDAHULUAN

Air susu ibu (ASI) merupakan makanan atau pun cairan awal yang masuk kedalam tubuh bayi dari pertama lahir. Menurut Prasetcyo, (2009) dalam Septikasari, (2018) mengatakan bahwa ASI eksklusif merupakan makanan yang terbaik untuk bayi yang hanya diberikan pada bayi hingga enam bulan tanpa ada tambahan cairan lainnya seperti susu formula, jeruk madu, air teh, dan air putih serta tambahan makanan padat seperti pisang, bubur susu, biscuit, bubur nasi dan nasi tim kecuali vitamin, mineral dan obat. Sedangkan makanan pendamping asi (MPASI) menurut Zami, (2018) MPASI adalah memberikan makanan pendamping ASI diberikan kepada bayi pada usia 6 bulan hingga 180 hari.

Fenomena pemberian MP-ASI diusia dini pun memiliki persentase cukup tinggi terutama di Indonesia, bersumber pada SDKI tahun 2017 bayi yang berusia 4-5 bulan memeroleh makanan pendamping ASI secara dini sebesar 57\%, $8 \%$ diberi susu formula sebesar $8 \%$ diberi air putih 10\% (Mariana dkk, 2016). Pemerintah Indonesia juga menetapkan keputusan baru menkes sebagai pelaksanaan kode etik World Health Organization. Keputuan tersebut mencantumkan tentang pemberian ASI eksklusif Permenkes No. 45/menkes/SK/V/2004. Pemerintah juga mengatur tentang makanan pendamping ASI MPASI dalam peraturan no 237/1997. Penting ditegaskan bahwa MPASI bukanlah makanan pengganti ASI tetapai MPASI adalah makanan pendamping ASI (Prabantini, 2010).

Hasil Riskesdas di provinsi Kalimantan Barat pada Tahun (2018) tentang proporsi pemberian makanan prelakteal pada bayi yang beumur 0-6 bulan sebanyak $33,5 \%$. Adapula jenis-jenis dalam pemberian MPASI yakni seperti air putih, teh manis, nasi yang dihaluskan dll. Presentase pemberian MPASI dengan air 
putih sebanyak $4,80 \%$ sedangksan pemberian MPASI dengan teh manis sebanyak $14,10 \%$ sebaliknya MPASI diberikan dengan nasi yang dihaluskan sebanyak $4,20 \%$.

Salah satu peristiwa peradangan saluran pencernaan dan pernafasan akibat pemberian MPASI dini menggambarkan salah satu pemicu tingginya angka kematian bayi di Indonesia (Depkes, 2009). Akibat negatif dari pemberian MPASI dini tersebut sesuai dengan studi yang dilakukan oleh Pusat Penelitian dan Pengembangan gizi yakni bayi yang diberi ASI parsial lebih banyak yang mengalami diare, batuk pilek, serta panas dari pada bayi yang diberi ASI predominan (Kumalasari dkk, 2015).

Bersumber pada hasil riset pendahuluan yang dilakukan di daerah kerja Puskesmas Siantan Tengah, bertepatan pada tanggal 29 Januari 2020 ada 10 orang ibu yang memberikan MPASI dini kepada bayi yang beumur 0-6 bulan. Hasil wawancara dengan sepuluh orang ibu yang berada di daerah Puskesmas Siantan Tengah, pada tanggal 29 Januari 2020. Terdapat 4 orang ibu yang berkata bahwa mereka memberikan MPASI dini kepada bayinya yang 0-6 bulan disebabkan sosial budaya disekitar mereka, serta 4 orang ibu yang berkata bahwa mereka memberikan MPASI dini kepada bayi yang berusia $0-6$ bulan disebabkan aspek kurang terpaparnya informasi, sebaliknya 2 orang ibu yang berkata bahwa mereka memberikan MPASI dini pada bayinya yang berumur 06 bulan disebabkan bayi rewel, dan produksi ASI tidak lancar.

\section{METODE PENELITIAN}

Metode penelitian ini memakai metode kuantitatif dengan pendekatan cross sectional. Kuesioner yang digunakan memakai google form dan telah melewati uji validitas. 
Dalam riset ini yang dijadikan populasi merupakan seluruh ibu yang mempunyai bayi berumur 0-12 bulan. Jumlah ibu yang memiliki bayi berusia 012 bulan yang terletak di daerah kerja Puskesmas Siantan Tengah Kota Pontianak yakni sebanyak 30 respnden. Teknik sampling yang gunakan dalm riset ini yaitu teknik total sampling dimana seluruh populasi yang terdapat pada saat penelitian dilakukan dan sesuai dengan kriteria inklusi dijadikan sampel penelitian. Seluruh ibu yang memberikan MPASI dini serta mempunyai bayi berumur 0-12 bulan. Artinya populasi yang ditemui oleh periset dijadikan sebagai sampel dengan jumlah 30 responden.

Kriteria Insklusi dalam penelitin ini ialah Ibu yang mempunyai bayi berumur 012 bulan, Ibu yang sudah memberikan MPASI dini, Ibu yang telah memberikan MPASI dini di daerah kerja Puskesmas
Siantan Tengah, Bersedia menjadi responden riset ini.

Penelitian ini telah uji lolos uji etik penelitian di STIKes Yarsi Pontianak dengan nomor

074/KEPK/STIKes.YSI/VIII/2020.

\section{HASIL}

1. Analisis Univariat

Tabel 1.1

KArasteristik Responden di Wilayah Kerja Puskesmas Siantan Tengah

\begin{tabular}{lcc}
\hline \multicolumn{1}{c}{ Variabel } & $\begin{array}{c}\text { Jumlah } \\
(\mathrm{n})\end{array}$ & $\begin{array}{c}\text { Presentase } \\
(\%)\end{array}$ \\
\hline Usia & & \\
Remaja Akhir & 13 & 44 \\
Dewasa awal & 17 & 56 \\
\hline Tingkat Pendidikan & & \\
Tidak Tamat SD & 5 & 16,7 \\
SD & 6 & 20,0 \\
SMP & 8 & 26,7 \\
SMA & 9 & 30,0 \\
PT & 2 & 6,7 \\
\hline Pekerjaan & & \\
IRT & 16 & 53,3 \\
Wirswasta & 9 & 30,0 \\
Karyawan & 1 & 3,3 \\
Buruh & 2 & 6,7 \\
$\quad$ Lain-lain & 2 & 6,7 \\
\hline Tingkat & & \\
pengetahuan & & \\
Baik & 21 & 70,0 \\
Kurang & 9 & 36,0 \\
\hline Social Budaya & & \\
Mengikuti budaya & 20 & 66,7 \\
Tidak $\quad$ mengikuti & 10 & 33,2 \\
budaya & & \\
\hline
\end{tabular}


Tabel 1.1 membuktikan responden berumur di rentang Dewasa awal yaitu 17 (56\%) lebih besar dibanding responden dengan umur rentang remaja akhir ialah 13 (44\%). Tingakat pendidikan respon yang paling tinggi sebanyak 9 (30\%) dibanding tingkat pendidikan PT sebanyak $2(6,7 \%)$. Sebanyak 16 (53\%) responden dengan kategori mayroritas ialah IRT dibanding dengan kategori yang sangat sedikit ialah buruh serta kariawan 2 (6,7). Responden dengan tingkatan pengetahuan yang baik lebih lebih besar ialah $21(66,7)$ dibanding dengan kategori pengetahuan cukup sebanyak 9 (36\%). Responden yang mengikuti budaya sebesar $20 \quad(66,7)$ sebaliknya yang tidak mengikuti budaya sebesar10 $(33,2)$

\section{Analisis Bivariat}

\section{Tabel 2. Faktor Yang Mempengaruhi Pemberian Mpasi Dini}

\begin{tabular}{|c|c|c|c|c|c|c|c|}
\hline & \multicolumn{4}{|c|}{ MPASI Dini } & \multirow[t]{3}{*}{$\sum$} & \multirow[t]{3}{*}{$\%$} & \multirow{3}{*}{$\begin{array}{c}P \\
\text { value }\end{array}$} \\
\hline & \multicolumn{2}{|c|}{$\mathrm{Ya}$} & \multicolumn{2}{|c|}{ Tidak } & & & \\
\hline & $\mathrm{N}$ & $\%$ & $\mathrm{~N}$ & $\%$ & & & \\
\hline $\begin{array}{l}\text { Tingkat Pengetahuan } \\
\text { Baik } \\
\text { Kurang }\end{array}$ & $\begin{array}{l}2 \\
6\end{array}$ & $\begin{array}{c}6,7 \\
20,0\end{array}$ & $\begin{array}{c}19 \\
3\end{array}$ & $\begin{array}{l}63,3 \\
10,2\end{array}$ & $\begin{array}{l}21 \\
9\end{array}$ & $\begin{array}{l}70,0 \\
30\end{array}$ & 0,001 \\
\hline $\begin{array}{l}\text { Sosial Budaya } \\
\text { Mengikuti budaya } \\
\text { Tidak mengikuti budaya }\end{array}$ & $\begin{array}{l}1 \\
7\end{array}$ & $\begin{array}{c}3,3 \\
23,3\end{array}$ & $\begin{array}{c}19 \\
3\end{array}$ & $\begin{array}{l}63,3 \\
10,0\end{array}$ & $\begin{array}{l}20 \\
10\end{array}$ & $\begin{array}{l}66,7 \\
33,3\end{array}$ & 0,000 \\
\hline
\end{tabular}

Dari table 2. Proporsi responden yang bayinya telah di beri MPASI dini dengan tingkat pengetahuan baik sebanyak $2(6,7 \%)$ dan reponden dengan tingkat pengetahuan yang kurang sebanyak 6 (20\%). Sebaliknya proporsi responden yang bayinya tidak di berikan MPASI dini dengan tingkat pengetahuan baik 19 (70\%) serta responden dengan tingkatan pengetahuan kurang sebanyak $3(10,2 \%)$. Hasil uji statistic chi square diperoleh 0,001. Hasil uji tersebut membuktikan ada pengaruh yang bermakna antara tingkat pengetahuan responden dengan pemberian MPASI dini.

Proporsi responden yang menberikan bayinya MPASI dini dengan mengiuti 
budaya sebanyak $1(3,3 \%)$ serta yang tidak mengikuti budaya sebanyak $7 \quad(23,3)$, sebailknya dengan responden yang memberikan bayinya MPASI dini dengan mengikuti budaya sebanyak $19(63,3 \%)$ dan yang tidak mengikuti budaya sebanyak 3 (10\%). Hasil uji statistic chi square diperoleh 0,000. Hasil uji tersebut membuktikan ada pengaruh yang bermakna antara Sosial budaya responden dengan pemberian MPASI dini.

Pengaruh Tingkat Pengetahuan Ibu dengan Pemberian MPASI Dini

Dari hasil analisis diketahui responden yang bayinya telah di beri MPASI dini dengan tingkatan pengetahuan baik sebanyak $2(6,7 \%)$ serta reponden dengan tingkat an pengetahuan yang kurang sebanyak 6 (20\%). Sebaliknya proporsi responden yang bayinya tidak di berikan MPASI dini dengan tingkat pengetahuan baik $19(70 \%)$ serta responden denga tingkatan pengetahuan kurang sebanyak 3
(10,2\%). Hasil uji statistic chi square diperoleh 0,001. Hasil uji tersebut membuktikan ada hubungan yang bermakna antara tingkat pengetahuan responden dengan pemberian MPASI dini.

Pengetahuan menurut Wawan \& Dewi (2014) pengetahuan merupakan hasil "tahu" serta terjalin setelah orang mengadakan pengindraan terhadap sesuatu objek terjalin lewat panca indra manusia ialah penglihatan, pendengaran, penciuman, ataupun rasa dan raba sendiri. Pada waktu pengindraan hingga menciptakan pengetahuan sangat di pengaruhi oleh keseriusan atensi anggapan terhadap obyek. Sebagian besar manusia berpengetahuan bisa diperoleh dari apa yang dilihat serta apa yang didengarnya.

Sebagian besar ibu sudah memberikan MPASI dini pada bayi umur 06 bulan. Demikian pula yang dinyatakan oleh (Notoatdmodjo, 2012), Pengetahuan dipengaruhi oleh aspek pendidikan formal serta sangat erat hubungannya. Diharapkan 
dengan pendidikan yang tinggi hendaknya akan semakin luas pengetahuannya. Namun orang yang berpendidikan rendah tidak berarti berpengetahuan rendah pula. Kenaikan tingkat pengetahuan tidak juga diperoleh dari pendidikan.

Menurut Kumalasari dkk, (2015) bahwa pada penelitiannya ada pengaruh secara bermakna antara tingkatan pengetahuan ibu dengan pemberian MPASI dini pada bayi umur 0-6 bulan. Prihal ini juga Sejalan dengan penelitian Helmi dan Lupina, (2012) Pada penelitian Helmi dan Lupina, pemberian MP-ASI dini lebih banyak terjadi pada bayi yang memiliki ibu dengan pengetahuan yang kurang baik ialah sebesar $54,5 \%$ dibanding bayi yang memiliki ibu dengan pengetahuan yang baik yaitu sebesar $16,1 \%$ dengan $\mathrm{p}$ value $<0,05$

Berikutnya bersumber pada pengakuan responden dengan kategori pengetahuan baik dan cukup, dengan alasan mereka telah memberikan MP-ASI pada bayi semenjak umur di bawah 6 bulan disebabkan kurangnya informasi tentang pemberian MP-ASI yang benar. Responden mengenalkan makanan tambahan semacam susu formula dan makanan lunak pada usia 0-6 bulan agar anaknya kenyang kemudian tertidur pulas, bila anak diberi makan pisang sewaktu berusia 2 bulan supaya anak tidak rewel serta lebih tenang, berat badan anak akan meningkat dan lebih cepat besar. Prihal ini disebabkan ketidaktahuan ibu tentang manfaat dan cara pemberian MP-ASI yang benar dan kebiasaan pemberian MP-ASI yang tidak tepat.

\section{Pengaruh Sosial Budaya Ibu dengan Pemberian MPASI Dini}

Responden yang menberikan bayinya MPASI dini dengan mengiuti budaya sebanyak $1(3,3 \%)$ dan yang tidak mengikuti budaya sebanyak $7 \quad(23,3)$, dibanding dengan responden yang memberikan bayinya MPASI dini dengan mengikuti budaya sebanyak $19(63,3 \%)$ dan yang tidak mengikuti budaya sebanyak 3 
(10\%). Hasil uji statistic chi square diperoleh 0,000. Hasil uji tersebut membuktikan ada pengaruh antara Sosial budaya responden dengan pemberian MPASI dini.

Dalam peneltian ini responden masih sangat banyak yang mengikuti budaya dalam memberikan MPASI dini dibanding untuk mentaati anjuran dari Pemerintah yang mengatur makan pendamping ASI (MPASI) dalam peraturan no 237/1997. Demikian pula penelitian yang telah dilakukan oleh Kumalasari dkk (2015), bahwa terdapat pengaruh antara sosial budaya dengan pemberian MPASI dini. Sosial budaya merupakan seluruh prihal yang diciptakan oleh manusia dengan pemikiran serta budi nuraninya dalam kehidupan bermasyrakat. Adapun lebih singkatnya manusia membuat suatu berbersumber pada budi serta pemikirannya yang diperuntukkan dalam kehidupan bermasyarakat serta menjadikannya suatau budaya.

\section{KESIMPULAN}

Berdasarkan hasil penelitiantentang faktor-faktor yang mempengaruhi pemberian MPASI dini di wilayah kerja Puskesmas Siantan Tengah dapat disimpulkan sebagai berikut :

1. Karakteristik responden

Usia responden dalam penelitian sebagian besar responden sebanyak 17 repoden yang remaja akhir (17-25) (56\%) serta pada responden dewasa awal (26-33) sebanyak 13 responden sebesar 43\%. Responden sebagain besar berpendidikan tamat SMA sebanyak 9 repoden sebesar $30,0 \%$ serta sebagian besar responden berpendidikan Perguruan Tinggi (PT) sebanyak 2 responden sebesar $6.7 \%$. Sebagian besar pekerjaan responden merupakan IRT sebanyak 16 responden sebesar $(53,3 \%)$ dan sebagian besar pekerjaan responden merupakan karyawan sebanyak 1 responden sebesar $(3,3 \%)$. Tingkatan pengetahuan responden di wilayah kerja 
puskesmas siantan tengah dengan kategori baik sebanyak 21 responden ialah sebesar 70,0\% serta nilai terendah dengan kategori cukup sebanyak 9 responden sebesar $36.0 \%$. responden yang mengikuti budaya sebanyak 20 reponden ialah sebesar $66.7 \%$ dan responden yang tidak mengikuti budaya sebanyak 10 reponden yaitu sebesar $33,3 \%$.

2. Terdapat pengaruh antara tingkat pengetahuan dengan pemberian MPASI dini pada bayi umur 0-12 bulan di daerah kerja Puskesmas Siantan Tengah dengan kategori baik sebanyak 21 responden ialah sebesar $70,0 \%$ serta dengan kategori cukup sebanyak 9 responden sebesar $36.0 \%$.

3. Terdapat pengaruh antara sosial budaya dengan pemberian MPASI dini pada bayi umur 0-12 bulan di wilayah kerja Puskesmas Siantan Tengah sebagian besar yang mengikuti budaya sebanyak 20 reponden yaitu sebesar $(66.7 \%)$ dan responden yang tidak mengikuti budaya sebanyak 10 reponden ialah sebesar $(33,3 \%)$.

\section{UCAPAN TERIMA KASIH}

Puji serta syukur kami panjatkan kehadirat Allah SWT, oleh karena Rahmat serta Karunia-Nya, penelitian ini bisa diselesaikan dengan baik. Tidak lupa shawalat dan salam kita haturkan kepada junjungan kita Nabi Muhammad Shallallahu 'Alaihi wa Sallam, yang membawa kita kepada cahaya yang terang benderang.

Pada peluang ini, kami sangat berterima kasih telah mendapat kesempatan menyusun penelitian ini. Ucapan terima kasih sebesar-besarnya kami sampaikan kepada yang terhormat:

1. Ketua STIKes YARSI Pontianak, Ibu Fajar Yousriatin, M.Kes., atas motivasi dan dukungannya demi terselesaikannya laporan penelitian ini.

2. Ketua Lembaga Penelitian dan Pengabdian Masyarakat Ibu Ns. Diena 
Juliana, S. Kep., M. Kes., atas motivasi demi terselesainya laporan ini.

Zami, B. (2018). MPASI With Love Makanan Pendamping ASI Terlengkap. Jakarta:Wahyu Media

3. Ketua Prodi Pendidikan Profesi Ners, Ibu Ns. Yunita Dwi Anggreyni, M.Kep., yang telah memberikan kesempatan dan motivasi untuk mengembangkan diri.

\section{REFERENSI}

Kumalasari, S, dkk. (2015). Faktor-faktor Yang Berhubungan Dengan Pemberian Makanan Pendamping ASI Dini. Ilmu Keperawatan Universitas Riau. 2, (1https://jom.unri.ac.id/index.php/JOM $\underline{\mathrm{PS}}$ IK/article/view/5211/5090).

Mariani, N, dkk. (2016). Faktor-Faktor Yang Berhubungan Dengan Pemberian Mp-Asi Dini Di Wilayah Kerja Uptd Puskesmas Sindanglaut KecamatanLemahabang Kabupaten Cirebon. Jurnal Kesehatan. 8,(3), (420426).

Prabantini, D. (2010). A to Z Makanan Pendamping ASI Si Kecil Sehat dan Cerdas Berkat MPASIRumahan. Yogyakarta: C.V Andi.

Septikari, M. (2018). Status Gizi Anak dan Faktor yang Mempengaruhu. Yogyakarta:UNY Press

Wawan, A \& M. Dewi. (2014). Teori \& Pengukuran Pengetahuan, Sikap, Dan Perilaku Manusia. Yogyakarta: Nuha Medika. 